\title{
Discovery of Vespasiano Bignami paintings at the National Theatre of Costa Rica through technical photography and UV-Vis spectroscopy
}

\author{
Geraldine Conejo-Barboza ${ }^{1,2,3}$, Eduardo Libby ${ }^{1,2}$, Carmen Marín ${ }^{4}$ and O. A. Herrera-Sancho ${ }^{2,3,5,6^{*}}$ (1)
}

\begin{abstract}
Establishing and understanding large format paintings are key to provide accurate information about the artist's palette and developing conservation strategies. Therefore, investigating the artworks of a population offers insight into its culture, history and origins which reveals individual and collective identity through cultural heritage worldwide. Particularly, the ceiling of the Foyer at the National Theatre of Costa Rica (Central America) is decorated with three large format paintings from the nineteenth century made by the Italian painter Vespasiano Bignami. The paintings are known as La Poesía, La Música and La Danza (The Poetry, the Music and The Dance) and have undergone restorations in the past. However, their state of conservation is unknown and thus demands accurate scientific examination in order to document their status and the extent of undocumented previous restoration work. To overcome those issues, we propose the application of a combination of non-invasive and in-situ techniques to carry out a qualitative assessment of the pigments and actual state of conservation. Here, we employed technical photography in the visible and near infrared regions, using panoramic stitching techniques in order to obtain high resolution images of the very large artworks. Several conservation problems were observed such as: detachment of pigments, cracks, stains, and sections with undocumented restorations. In the IR and False Colour Infrared images we observed a very conspicuous behaviour of the red pigment used in the three paintings. Particular areas with the red pigment were fluorescent, and by means of ultraviolet fluorescence imaging we identified the pigment as through its red-coral fluorescence as Madder Lake, by comparison to a historical pigments reference palette. Measurements in five different red pigmented zones using UV-Vis spectroscopy in The Music show bands in the (550-650) nm region. A Lorentz Model nonlinear curve fit to the bands allowed us to correlate the fluorescent pigment in the paintings of Vespasiano Bignami with Madder Lake.
\end{abstract}

Keywords: Madder lake, Technical photography, Fluorescent, Costa Rica, UV radiation, Spectroscopy

\section{Introduction}

Nature has always amazed us by the colours it generates, interpretation and use of colour have been part of humankind since ancient times and until today, as said

\footnotetext{
${ }^{*}$ Correspondence: oscar.herrerasancho@ucr.ac.cr

${ }^{2}$ Centro de Investigación en Ciencia e Ingeniería de Materiales (CICIMA),

Universidad de Costa Rica, 2060 San Pedro, San José, Costa Rica

Full list of author information is available at the end of the article
}

by Iqbal and Hao "colour is an important and ubiquitous part of our everyday life and ever since pre-historic times, colours, be they inorganic or organic, have had profound anthropological, psychological, aesthetic, functional and economic impact on society" [1]. The pictorial materials used by artists throughout history are strongly linked to their material availability in nature, production technology and trends of the respective epochs. For this reason, pigments can be decisive time indicators in many cases.
Springer Open

(c) The Author(s) 2020. This article is licensed under a Creative Commons Attribution 4.0 International License, which permits use, sharing, adaptation, distribution and reproduction in any medium or format, as long as you give appropriate credit to the original author(s) and the source, provide a link to the Creative Commons licence, and indicate if changes were made. The images or other third party material in this article are included in the article's Creative Commons licence, unless indicated otherwise in a credit line to the material. If material is not included in the article's Creative Commons licence and your intended use is not permitted by statutory regulation or exceeds the permitted use, you will need to obtain permission directly from the copyright holder. To view a copy of this licence, visit http://creativeco mmons.org/licenses/by/4.0/. The Creative Commons Public Domain Dedication waiver (http://creativecommons.org/publicdomain/ zero/1.0/) applies to the data made available in this article, unless otherwise stated in a credit line to the data. 
Paintings are one of the most striking means that human beings have used to share our history, learning, personal beliefs and thoughts. Paintings reflect the connection between the artist and its time, not only in the thematic and stylistic aspects, but in the availability of art materials such as pigments, binders and varnishes. Establishing and understanding these relations are key to provide accurate information about the artist's palette and developing conservation strategies.

Artists historically have found inspiration in the colours of Nature, and have made efforts to expand the colour range of inorganic pigments by using plant dyes [2] A good example is the important Carmine Red (from cochineal insect) dye which was produced in Perú and México in Pre-Hispanic times and was used as a dyestuff. When combined with several mordants and salts, it produces a variety of Lake pigments with different hues of red [3]. This red pigment, when found, can then be used as a marker associated with the Spanish conquest, regarding the fact it was commercially available in Europe since the sixteenth century when was started to be used in paintings $[4,5]$.

To understand the history around an artist's palette is necessary to identify the pigments used in the artwork, this also affords valuable scientific information for developing adequate conservation strategies worldwide. A pigment with a very strong connection between time and industry is Madder Lake. It was used first as dye for textiles when it was manufactured in the early sixteenth century B.C in Egypt [6], in book illustrations [6], in Rome ceramics along with other archaeological objects [7-10], and later on a pigment in paintings $[6,11,12]$. In spite of its commercial success, the use of Madder Lake decayed when Alizarin, one of its main components, started being produced by synthetic means in 1869 by the chemists Graebe and Liebermann. Finally, it actually becomes the first natural dye to be produced in the laboratory [13] causing, as a consequence, a vigorous decrease in the use of natural Madder Lake.

One of the most useful properties of Madder Lake is its fluorescence under ultraviolet light (UV). Its fluorescence allows the identification of Madder Lake in paintings by using non-invasive methods, such as UV-Visible spectroscopy. There are interferences from the fluorescence of binding media $[14,15]$ additionally with low intensity bands of other components of the painting. Nevertheless, an advantage is that this technique is non-invasive and low-cost in comparison with chromatographic techniques and surface enhanced Raman spectroscopy (SERS) that require extraction of samples or more expensive equipment [16]. UV-induced visible fluorescence can be then used as a low cost technique for preliminary examination thanks to the particular red-orange fluorescent colour of Madder Lake. It is worth mentioning that this pigment has been detected in many cultural heritage objects, see $[12,14]$ and references therein for further details.

Another important non-invasive, preliminary diagnostic technique is the use of technical photography to create high resolution images in the visible (Vis) and Near Infrared (IR) region of the electromagnetic spectrum. The photographs can be taken by using a digital camera in which the sensor's low-pass filter is removed and replaced with a material transparent to UV, Vis together with IR light. With images from the Vis and IR region, it is possible to create an infrared false color image (IRFC) by which to obtain information a preliminary qualitative identification of a pigment, such as in this case of Madder lake. An additional benefit of this technique is that is also possible to discover previous restorations attempts. The images can be used for establishing a timeline and follow the state of conservation of the artwork [17].

The aim of this study is to investigate qualitatively the pictorial palette and the state of conservation of three great nineteenth century paintings at the National Theatre of Costa Rica, known as La Poesía, La Música and La Danza (The Poetry, The Music and The Dance), made by Vespasiano Bignami, through the application of low-cost, non-invasive and in-situ techniques, such as UV-Vis spectroscopy and technical photography. An important consideration while examining these artworks, is that the executive techniques traditionally used in Europe were not designed to withstand the effects of the climate and humidity of the tropics in Latin America. Deterioration caused by these extreme tropical conditions is still largely unstudied, underscoring the importance of the present research as a first starting point towards establishing affordable multidisciplinary methodologies on cultural heritage worldwide.

In the next sections we present a brief history of Vespasiano Bignami and his paintings, followed by the application of our experimental set up to the examination of the paintings. We continue with our main results and discussion regarding the state of conservation and the identification of Madder lake. Lastly, we finish with concluding remarks and detailed experimental methods and data.

\section{Vespasiano Bignami}

One of the most important aspects of studying the work of an artist is that art is always linked both to the artist's personal history and also to the history of a country and its society: It is a reflection of a specific moment in time. Studying Vespasiano Bignami is taking a look into CostaRican society and history, regarding the fact that Bignami was in charge of the three largest paintings for one of the 
most important cultural buildings of the nineteenth century in Costa Rica.

Vespasiano Bignami was an Italian painter, illustrator, and caricaturist active in the "Scapigliatura", a late nineteenth century Italian literary movement and he adhered to the artistic current of Lombard Impressionism [18]. Born in Cremona, after his training at the Academy of Bergamo he began his artistic career in Milan, also teaching at the Brera Academy [19]. Most of the works of Vespasiano were oil paintings and some watercolors, the majority of which are nowadays conserved in Italy. His most iconic oil paintings are mentioned in Table 1 [2024]. These oil paintings as far as we know, have not been studied by scientific means, for that reason, is not possible to establish similarities in technique and materials with those located at the National Theatre of Costa Rica.

The three paintings by Vespasiano Bignami which correspond to the artworks studied here, cover the entirety of the ceiling of the Foyer at the National Theatre of Costa Rica. The Foyer is a large area (roughly $176 \mathrm{~m}^{2}$ ) above the entrance lobby where people used to meet before a performance. Today, the Foyer is used for protocolary acts of the government, artistic presentations, and is also a tourist attraction. The National Theatre is then a building of great importance for the Costa Rican culture, society and economy.

The National Theatre of Costa Rica opened to public on October 21st, 1897. Subsequently it was declared National Monument in 1965 and more recently, in 2018 National Symbol according to Costa Rican Law \#9521. Inside the Theater, ornamentation was commissioned to contractors Molinari \& Riatti $[25,26]$, whom subcontracted the work to several Italian artists such as Carlo Ferrario, Roberto Fontana, Aleardo Villa, Antonio Rovescalli [27], and also to Vespasiano Bignami.

The three paintings created by Vespasiano are the largest in the Theatre and are representations or allegories of art -The Music, The Dance, and The Poetry-.

\begin{tabular}{|c|c|c|}
\hline Painting Name & Current location & Date \\
\hline Philosopher & $\begin{array}{l}\text { Picture Gallery of Carrara } \\
\text { Academy }\end{array}$ & 1862 \\
\hline Botanic Lesson & G. Verdi Conservatory & Post 1869 \\
\hline Portrait of Ignazio Peregalli & $\begin{array}{l}\text { Art Collection of Major } \\
\text { Hospital }\end{array}$ & Post 1884 \\
\hline Portrait of Francesco Osculate & $\begin{array}{l}\text { Art Collection of Major } \\
\text { Hospital }\end{array}$ & Post 1891 \\
\hline Portrait of Achille Nebuloni & $\begin{array}{l}\text { Art Collection of Major } \\
\text { Hospital }\end{array}$ & Post 1911 \\
\hline
\end{tabular}

Each painting was made in the Sforza Castle in Milan, and then sent to Costa Rica [28, 29]. The three paintings have in common their very large size as well as a similar colour palette. The lateral panels The Dance and The Poetry can be observed in Fig. 1.

In spite of their preponderance inside the building, these three paintings have not been subjected to a scientific examination in order to determine their state of conservation, or to document their pigment composition along with correlate its use of pigments with Vespasiano Bignami's technique. Therefore, this research will serve as a base for future studies and to investigate quantitatively the pictorial palette Vespasiano Bignami in other artworks worldwide.

\section{Methodology}

\section{Experimental set-up}

We employed a combination of non-invasive techniques such as technical photography, inspection with UV (ultraviolet) radiation, and UV-Vis (visible) spectroscopy, in order to determine the state of conservation of each painting. Analysis of technical photographs in the Vis, and IR regions, as well as IRFC (Infrared False Colour) images allowed us to carry out a qualitative evaluation of the pigments. Finally, in situ UV-Vis spectroscopy and fluorescence induced by UV radiation completed the identification of the pigments.

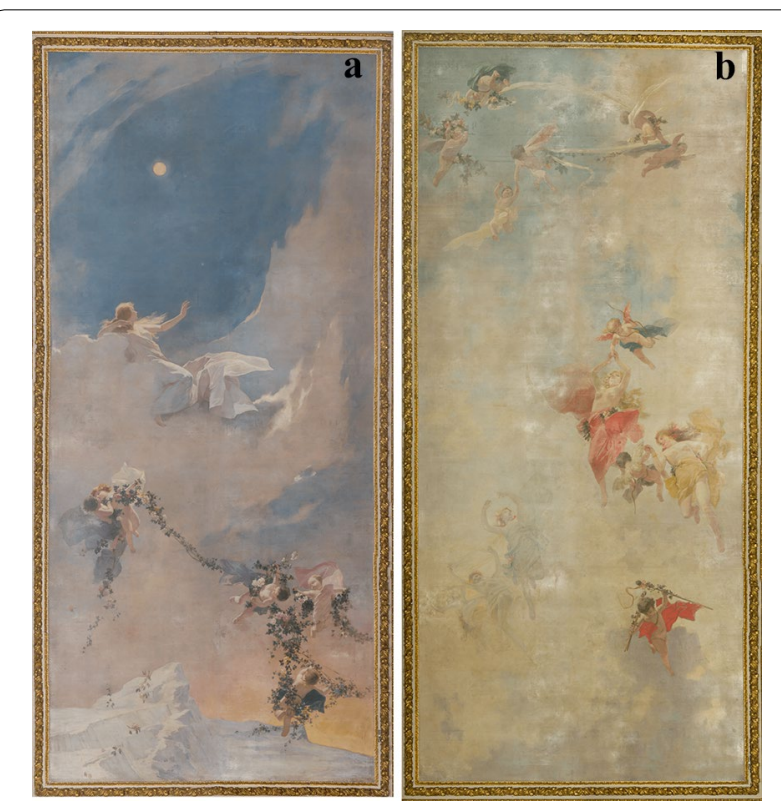

Fig. 1 Paintings a The Poetry ( $9.83 \mathrm{~m}$ length $\times 5.13 \mathrm{~m}$ wide) and $\mathbf{b}$ The Dance (9.83 m length $\times 5.13 \mathrm{~m}$ wide) located at the National Theatre of Costa Rica 


\section{Technical photography and state of conservation}

Technical photography has become one of the most important tools to assess the state of conservation throughout a painting. This procedure was employed for The Poetry, The Dance, and The Music to obtain high resolution images in the Vis and IR regions of the electromagnetic spectrum. The channels of IRFC were constructed using the luminosity channel of the infrared (IR) image and performing the usual channel substitution of the Vis image R, G, B channels into IR, R, G.

Photographs were acquired with a Nikon D7200 camera, modified for technical photography by Life Pixel, equipped with a AF-D Nikkor $50 \mathrm{~mm} \mathrm{f/1.8} \mathrm{objective.}$ Images were captured in the visible spectral range (Vis) 400 to $780 \mathrm{~nm}$ - by using a XNiteCC1 M52 filter and for the infrared range (IR) -780 to $1000 \mathrm{~nm}$-with a Heliopan RG1000 filter. For both ranges we used a exposure time of $4 \mathrm{~s}$, aperture at $\mathrm{f} / 11$, ISO 200 , using two halogen lamps of approximately $150 \mathrm{~W}$ for total illumination.

Prior to the photo shooting which was done by night to avoid as much as possible the city lights, it was necessary to cover six windows of the Foyer as the Theatre is located downtown in Costa Rica's capital city. We also employed a $4 \mathrm{~m}$ tall scaffold for examining the artworks in the ceiling. The image stitching process required that we kept the camera's sensor perfectly aligned with the ceiling while the camera was displaced horizontally on a tripod. We marked a grid on the floor to position the camera so there was enough image overlap for covering properly the whole painting and at the same time making sure we could mask out the "hot spot" of the IR region during the stitching.

Before starting the shooting of the Vis images a white balance calibration was made with an AIC target. The calibration and exposure remained unchanged for the IR images. The camera was manually focused and operated remotely using the tethering software Camera Control Pro 2 from Nikon. Images were stored directly into the computer's hard disk in RAW format for further processing. In order to obtain image registration to the pixel level, both the Vis and IR images were obtained at each position on the grid, and the camera was carefully refocused each time that a filter was changed for the Vis and IR photos. A total of 48 photograph pairs were acquired for the each of the two lateral paintings, The Poetry and The Dance and 202 photograph pairs for The Music in Vis and IR.

We used the following editing process for the Vis and IR RAW data (as.NEF) files. For the Vis images we created a colour-correction profile using a X-Rite Color Passport Checker ${ }^{\circledR}$ reference and the Color Checker Camera Calibration v1.1.1 software and applied it, together with the proper lens parameters profile, in Adobe Lightroom
Classic $^{\circledR}$. For the IR region the photos were exported from Lightroom and converted into grayscale files (the IR images). To accomplish the IRFC images, after converted into grayscale, simply replace the IR image to the Red channel of the VIS image. This procedure was carried out in the commercially available Adobe Photoshop ${ }^{\circledR}$ software.

To create the IRFC images for the three paintings, each photo pair from the Vis and IR was aligned in Adobe Photoshop ${ }^{\circledR}$ After the alignment the exchange of the RGB channels between the Vis an IR was applied as described. Each individual Vis, IR and the new IRFC image for each painting was exported in.TIFF format, and they were used to create a high-resolution panorama of the whole painting using PT Gui Pro ${ }^{\circledR}$ software.

If we now turn to observe the extent of previous restoration efforts, we used a UV lamp to inspect each painting at close range using the scaffold at $8 \mathrm{~m}$ height and allowing us to define the artwork's state of conservation. The lamp's source spectrum had two maxima: $\lambda_{1}$ at $370 \mathrm{~nm}$ with a power of about $2.45 \mathrm{~mW}$, and $\lambda_{2}$ at $436 \mathrm{~nm}$ with a power of roughly $1.69 \mathrm{~mW}$. The spectrum of the lamp is shown in Additional file 1: Figure S1. At these emission wavelengths, the lamp's radiation does not interfere with observing the fluorescence of varnishes, resins, or fluorescent pigments.

\section{UV-Vis spectroscopy}

Thanks to the inspection made with the UV radiation we observed several sections on the three paintings with a reddish-orange fluorescence. For that reason, we carried out measurements of UV-Vis spectroscopy induced by UV radiation for The Music on five different reddishorange fluorescent sections, and in a reference zone were no fluorescent was observed (see Fig. 2). We made these measurements only in this painting because has the most intense fluorescent zones of the three.

To carry out the UV-Vis induced fluorescence measurements an Avantes Model AvaSpec-2048 spectrometer with a grating set for (184-746) nm, coupled to an optical fiber was used. The measurement conditions were an integration time of $70 \mathrm{~ms}$ with an average of 30 scans to have a good signal to noise ratio and to avoid saturation on the optical fiber due to the UV radiation. The experimental design consisted on a set of three replicas per measurement.

To achieve an identification of the fluorescent pigment we fulfilled data analysis from each spectra as follows: first, a nonlinear curve fit (Lorentz Model) was applied to the band around $(550-650) \mathrm{nm}$. The latter was carried out in order to obtain information regarding the wavelength of the signal observed and also about the band's Full Width at Half Maximum (FWHM). This fitting 


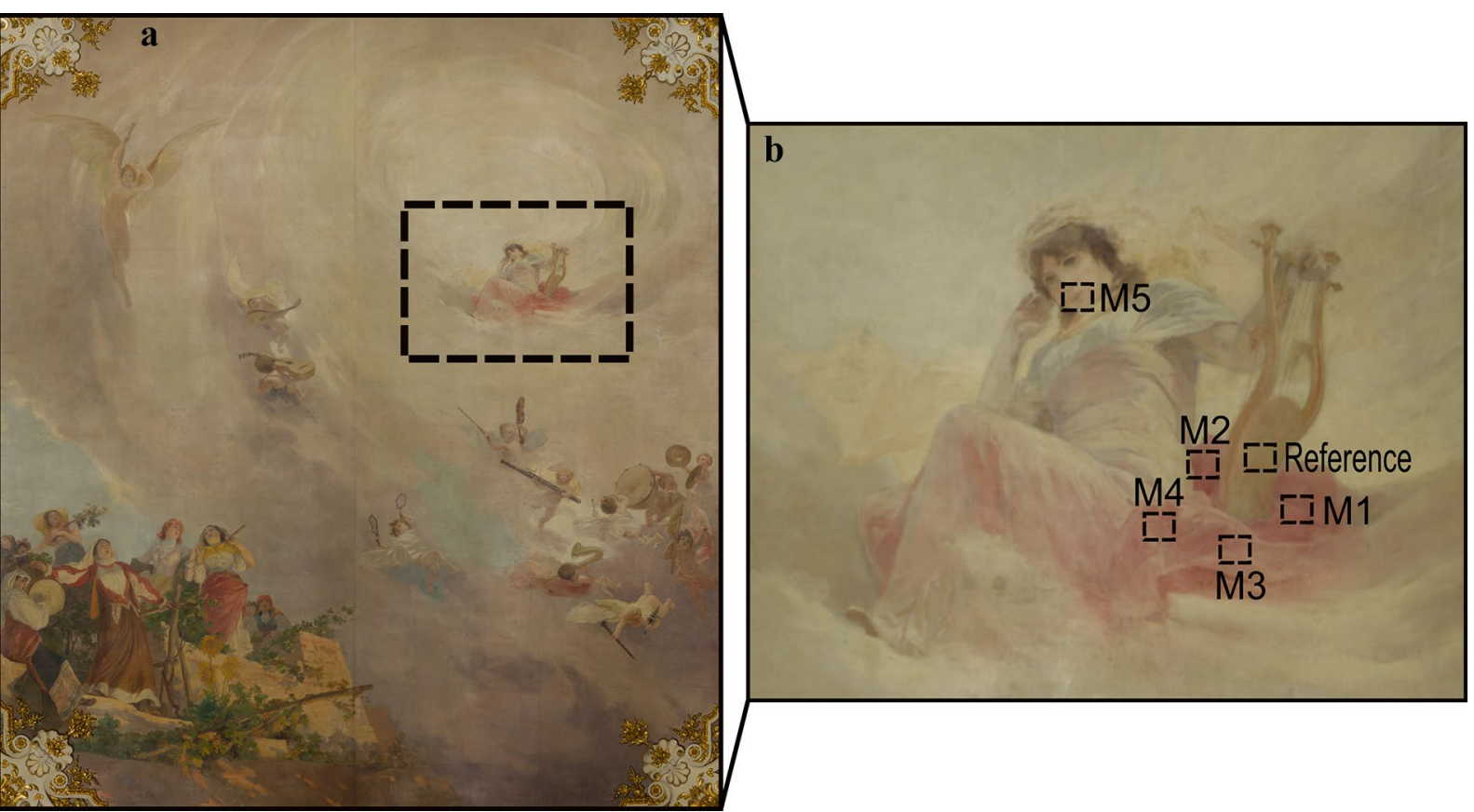

Fig. 2 a Panorama of The Music (9.51 m length $\times 8.84 \mathrm{~m}$ wide) artwork, $\mathbf{b}$ Section of The Music artwork showing the measurement points as M1 to $\mathrm{M} 5$, and the reference zone were the UV-Vis spectra were taken

was implemented by using the Origin Pro ${ }^{\circledR}$ software in accordance with the next formula:

$$
y=y_{0}+\frac{2 A}{\pi} \frac{w}{4\left(x-x_{c}\right)^{2}+w^{2}},
$$

where $y_{\mathrm{o}}$ is the offset with respect to $y, x_{\mathrm{c}}$ corresponds to the center of the curve, $w$ denotes the FWHM, and $A$ is the total area of the curve.

To validate our results for the identification of the fluorescent pigment, measurements on a fluorescent pigment (Madder lake) from the Pigment Checker from Cultural Heritage Science Open Source (CHSOS) [30] were realised in the same conditions used for the five zones on the painting. The same fitting for the spectral band was applied and the data obtained were plotted as a box plot for making comparisons using the RStudio ${ }^{\circledR}$ software.

\section{Results and discussion}

The history around a painting is a very important issue for a conservation proposal and to unveil possible relationships between pigments and artists. The paintings made by Vespasiano Bignami are only 122 years old; nevertheless, there is very little information regarding the conservation procedures applied to them since they were first displayed on the National Theater. For that reason obtaining that kind of information is key to create a timeline among the artist, the pigments and possible restorations.
There are records of at least four main interventions; nonetheless, no technical sheet of the materials and zones of intervention was documented for any of them. The first one was done in 1934 by the restorer Antolin Chinchilla, who made some retouches with oil-based pigments [31]. The second, in 1965, was in charge of the Instituto Nacional de Bellas Artes of Mexico, and was mostly related to conservation procedures on wood and cracks by using beeswax to avoid problems of humidity and leaks of water. The procedure was unsuccessful [31] due to the high ambient temperatures. The last two, which together took around ten years, started in 1970. A first stage was done by the Instituto Central de Conservación y Restauración de Obra de Arte of Spain [32], and later some additional works were done by the restorer Carmen del Valle [33-35]. To contribute to establishing the state of conservation of the three paintings, and create the first scientific documentation about these monumental works of art, we first employed detailed technical photography.

Photographs in the Visible (Vis) region made for The Poetry, The Music and The Dance, allow us to differentiate the original painting from the restorations. We were able to determine and document issues related to cracks, retouching with different types of strokes, stains, variation in colour, detachment of pigments, as well as marks from the wood boards, to which is applied the painting substrate. All these features are 
more evident in the IR images. These photographs correspond to the first experimental realization of high-resolution images and hence support us to establish an initial mark in time regarding their state of conservation.

As expected, all of the sections that were brighter in the IR images were also yellow in the IRFC. This is a first indication that the red pigment has the same composition on all of the three paintings. Features of the location of the pigments, and also the comparison among the Vis, IR and IRFC panoramas can be seen in Additional file 1: Figures S2-7. The information gathered about the pigments distribution can be of help for future works, for conduct an efficient sampling, and to design experiments without making measurements in a random way identifying in a non-destructive and non-invasive manner regions of interest.

Because the information obtained with the IRFC is not conclusive regarding the pigments composition, we used UV induced visible fluorescence. This is a method often chosen to obtain more information about the pigment identity, and it can improve the data about the state of conservation [36, 37]. At first, it was possible to observe zones in a darker colour that are associated with retouches of colour and are visible in all the three paintings. Furthermore, yellow-green fluorescence can be related to aged varnish, given that recent layers of resins and varnishes do not fluoresce. In those cases the material absorbed UV radiation and it appears as a dark purple [14]. Particularly, this was observed in the frames located in the center of The Music. With these inspections it became evident which sections had undergone restoration, and it will prove useful to identify conservation issues in each painting; information that was not previously available to our work.
In addition to the previous findings, the sections that were beforehand identified as brighter in the IR, and presented a yellow colour in the IRFC, indeed show a particular behaviour under the UV radiation as they exhibit a red-coral colour fluorescence. Closer examination demonstrates that these correspond only to some accented areas within a red-painted object such as flowers, ribbons, dresses, mouth, and a necklace. To have a more precise identification, the colour observed was compared with a reference palette of pigments (Pigment Checker from CHSOS [30]), which contains pigments from antiquity until early 1950.

Fluorescent pigments usually exhibit specific colours under UV light, so a visual comparison between the paintings and the reference palette (see Fig. 3 ) is a first step in the analysis. The comparison allowed the identification of the fluorescent pigment as Madder lake (Kremer-372051). The pigment in the paintings was used to enhance the shadows or to represent movement on the figures and plants. Madder Lake was mainly a colour accent taking into account that was a very expensive pigment [38]. Accordingly, its use was not so extensive in a painting, as was observed in Vespasiano Bignami paintings. A drawback to its confirmatory identification is that the colour hue observed could be also affected by mixing with other pigments, its particle size, and the binders used [39]. For this reason, the use of UV-Vis spectroscopy could be of help to characterize more precisely the fluorescence observed.

For the in situ measurements with the UV-Vis spectrometer five different zones on the painting The Music were selected, as was shown in Fig. 2. This painting was selected over the other two, because it shows a specific zone where the fluorescence was more intense. A comparison was made with the Pigment Checker from
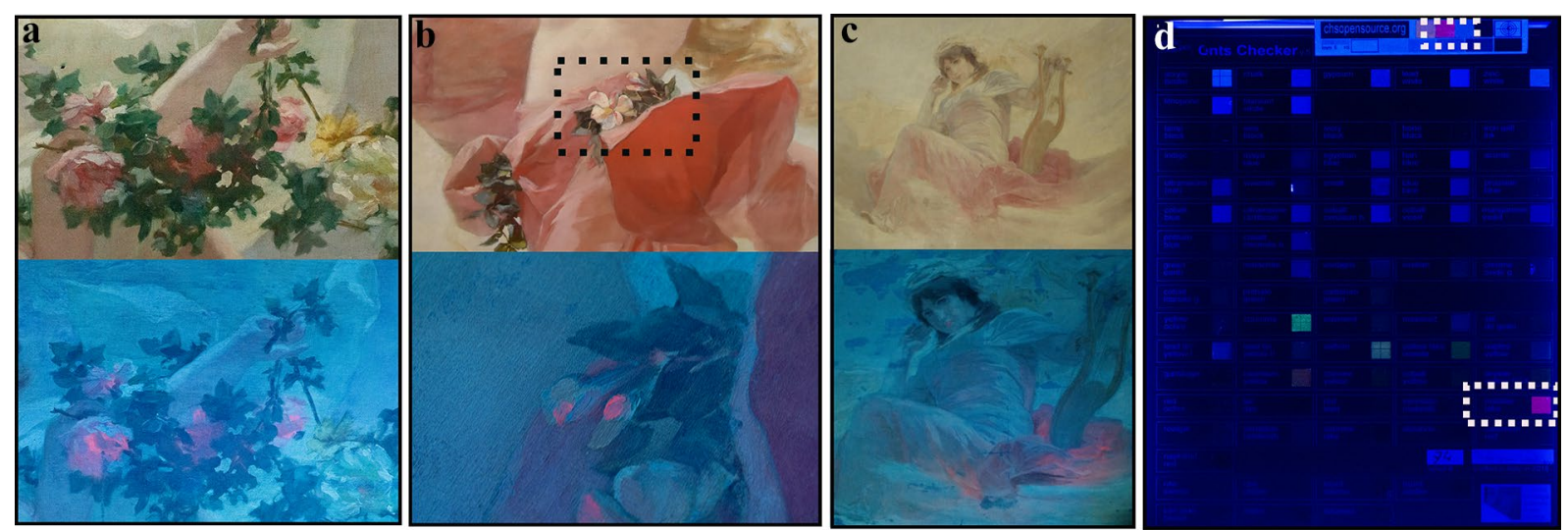

Fig. 3 Comparison between Vis and Fluorescent response under UV radiation in areas of a The Poetry, $\mathbf{b}$ The Dance, c The Music, and $\mathbf{d}$ Pigment Checker from CHSOS, white rectangles show the Madder lake 
CHSOS where the Madder lake is present in two different zones, to determine if the preparation on the pigment could affect the measurements of the spectra and therefore the colour observed.

For the UV-Vis measurements the center wavelength $\left(x_{c}\right)$ was calculated through a Lorentz fitting between the wavelength range (500-700) $\mathrm{nm}$ (see Eq. (1)). This range was selected because we observed a signal different from that of the source of irradiation (UV lamp). The average range for the five measurements zones goes from $582 \mathrm{~nm}$ to $602 \mathrm{~nm}$, and as it was expected for the reference, no signal was observed within that range. Figure 4 shows the spectra obtained from UVVis measurements done in The Music and in the Pigment Checker as well as a box plot with a comparison from our experimental data, and six values reported in the literature for Madder lake identification samples [8, 40-44].

The characteristic spectrum of a pigment usually correlates well with the observed colour. In Fig. 4a it is possible to observe variations among the measurements carried out on the painting (M1 to M5) in comparison with the measurements done on the Pigment Checker (M6 to M7), and within the same sample. These variations could be related to the method of manufacture of the Madder lake moreover to extraction and recipes procedures [45], also to self-absorption of the molecule and scattering effects [46-48], along with the application method of the artist.
The calculated value of $x_{\mathrm{c}}$ is sensitive to the mentioned factors, and the differences observed cannot be associated with just one them. Nevertheless, in Fig. 4a the $x_{c}$ range found among the measurements done on the painting (M1 to M5) is far larger than the measurements performed on the Pigment Checker (M6 to M7). The individual box plots show that our method is very precise as the individual $x_{c}$ data for each site are clustered closely together and thus variation among sampling sites can be assigned to a combination of factors that can affected the fluorescence response of the pigment.

The red dye in Madder is mainly a combination of the dyes alizarin (1,2-dihydroxyantraquinone), purpurin (1,2,4,-trihydroxyanthraquinone), and pseudopurpurin (1,2,4,-trihydroxyanthraquinone-3-carboxylic acid). Natural variation as well as the extraction method employed affects the proportions of these substances along with the spectrum of a Madder sample [47], and the observed colour [49]. It has even been found that some Madder Lake pigment varieties do not even show fluorescence at wavelength of $254 \mathrm{~nm}$ (UVF254) [50], therefore fluorescence response could be related to manufacture of the pigment, and the proportions of alizarin, purpurin and pseudopurpurin found in an specific sample of Madder lake.

We also compared our Madder lake center wavelength $\left(x_{c}\right)$ data to measurements found in the literature. The box plot was built with the $\mathrm{x}_{\mathrm{c}}$ obtained with Lorentz fitting of three replicas for measurement points from M1 to M3, and M6 and M7. One exception
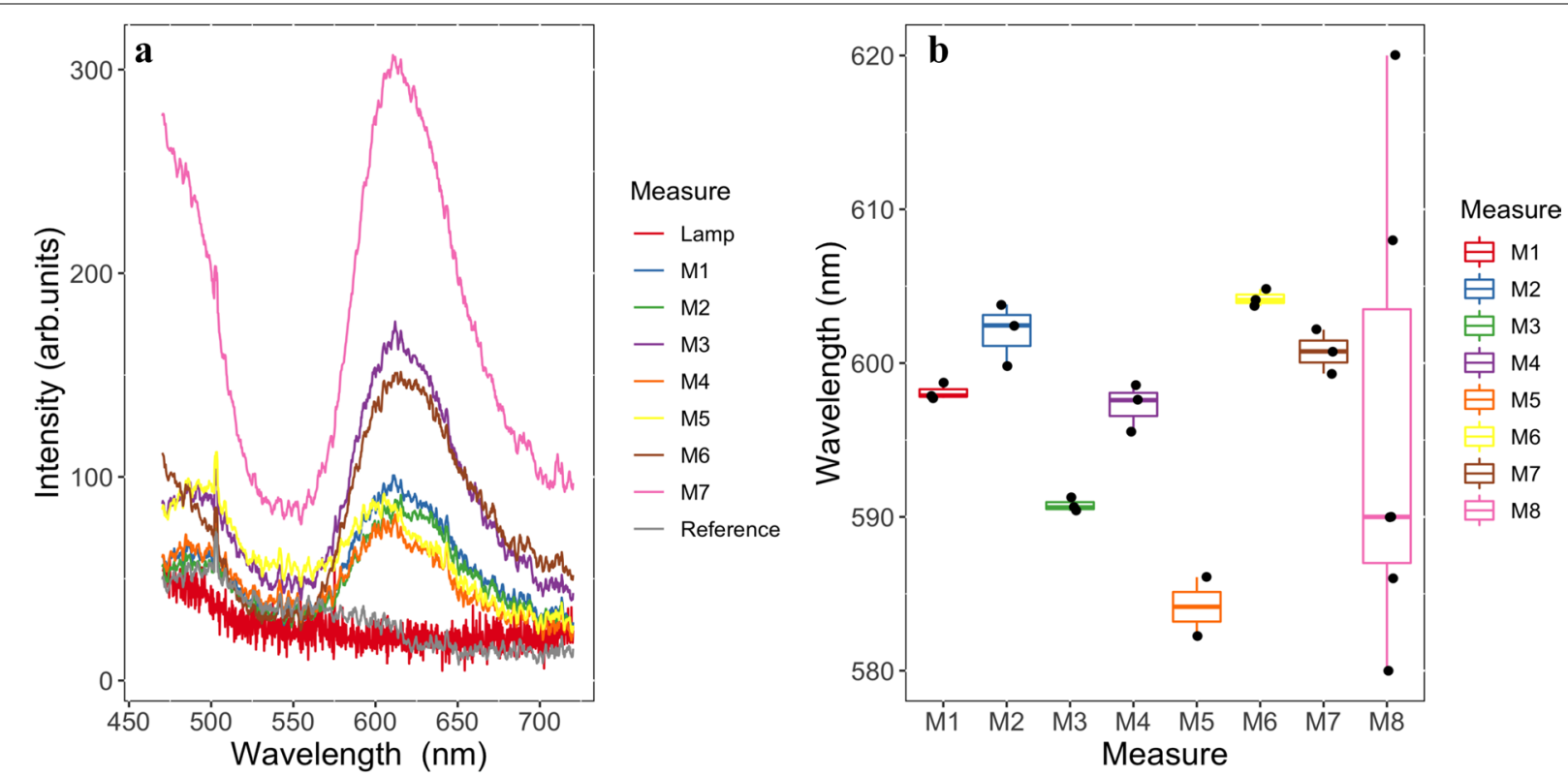

Fig. 4 a Measurements of UV-Vis in painting The Music (M1 to M5) showing the center wavelength $\left(x_{c}\right)$ and the measurements M6 and M7 for the Madder lake in the Pigment Checker, b Box plot with $x_{c}$ from painting The Music (M1-M5, see Fig. 2), Pigment Checker from CHSOS (M6-M7), and reference from literature (M8). Black points correspond to the experimental data 
is M5, for which only two of the three measurements allowed us to obtain a convergence for fitting. In our plot, M8 corresponds to experimental data collected from the literature. A striking aspect in Fig. 4b is that when fluorescence data found in the literature are plotted together with our results, we notice that there is an even larger range of reported values, and our data are consistent with the different reported data [41-45]. This comparison also evidences the variability in the $\mathrm{x}_{\mathrm{c}}$ of Madder lake, regarding the sample analyzed, the method of manufacture, and even the way in which the artist applies the pigment to the object.

An additional feature seen in Fig. $4 \mathrm{a}$ is the presence of a broad signal around 450-500 $\mathrm{nm}$ in the spectra for The Music (M1 to M5, see Fig. 2). This band is not observed in the spectra of the UV lamp, but it is seen in the reference spectrum which was measured on an area of the painting that does not fluoresce due to absence of Madder lake. This band could be related to the varnish or resin used on the painting. The band may be shifted by aging, and be associated to oxidation processes that generate fluorescent molecules. It is possible that the recipe, and the type of varnish used could affected the signal observed [51]. Those signals could be related to previous restorations.

Forty years ago a restoration process applied a varnish retouch to The Music. This varnish could be the cause of the (450-500) nm signals on the painting, which are very different to the band observed in the same range for M6 and M7 that belong to the pigment checker from CHSOS where the pigment is mixed with an acrylic resin. This varnish over the painting might also affect the colour observed in the fluorescent areas, as the particle size of the bulk (pigment plus varnish) could affect the perception of colour (scattering effect). An evaluation of the FWHM for measurements from M1 to M7 was carried out between (550-650) $\mathrm{nm}$. The latter in order to correlate the particle size and variations of the colour observed through the samples. Table 2 shows the median of the three replicas for each point, with the exception of M5 where it was calculated with two replicas. The FWHM is obtained from the Lorentz fit previously mentioned (see the UV-Vis spectroscopy section).

It is observed that in the measurements made on The Music (M1 to M5), there is a decrease in the FWHM that could be related to a small particle size, which in turn is correlated to a shorter wavelength observed in Fig. 4b, and accounting for the variation in the observed colour. Interestingly, the Madder lake samples from the Pigment Checker (M6 and M7), both have the same pigment composition mixed with an acrylic binder, nevertheless, there is a variation in the FWHM, which is an indication of how the preparation but also the scattering could affect
Table 2 Mean of FWHM calculated for five measurements on The Music and in two samples of Madder lake from the pigment checker from CHSOS

\begin{tabular}{ll}
\hline Location of measurement & $\begin{array}{l}\text { Median } \\
\text { of FWHM } \mathbf{f} \text { standard } \\
\text { deviation (nm) }\end{array}$ \\
\hline M1 & $70.8 \pm 1.3$ \\
M2 & $70.1 \pm 1.3$ \\
M3 & $70.2 \pm 1.2$ \\
M4 & $66.5 \pm 1.9$ \\
M5 & $42.7 \pm 1.5$ \\
M6 (Madder Lake from Pigment Checker) & $86.5 \pm 2.3$ \\
M7 (Madder Lake from Pigment Checker) & $73.1 \pm 1.4$ \\
\hline
\end{tabular}

the colour and also the $x_{\mathrm{c}}$ associated with the identification of a pigment.

\section{Conclusion}

Limited access to cultural heritage is a challenge to restoration scientists seeking to obtain information quickly, in a non-destructive and non-invasive manner, and specially to compare, for instance, the time evolution of artworks in highly-diverse environments. Despite its exploratory nature, the empirical findings in this study provide a new understanding of the pictorial palette and the state of conservation of three great nineteenth century paintings at the National Theatre of Costa Rica offering some insight into the few scenarios in which cultural heritage could be investigated in Central America along with Italy.

The evidence from this study suggests a qualitative identification of the fluorescent pigment as Madder lake in three paintings of Vespasiano Bignami, with the aid of low cost and in situ equipment such as a modified commercial digital camera, UV radiation, and UV-Vis spectroscopy. This identification method on The Music could also be extended to The Poetry and The Dance artworks, given the fact that comparable coloured areas are very similar not only on the visible spectrum images, but also on their behaviour in the IR and IRFC images. In addition, our most important finding was that our method for calculation of $x_{\mathrm{c}}$ gives very similar results to the reference and to previously studied samples with the same pigment.

In future investigations, it might be possible to use different techniques in order to carry out a qualitative assessment of the artist's main colour palette and actual state of conservation. Nevertheless, the information obtained is a first step to develop a technical data sheet about these paintings and about Vespasiano Bignami's techniques, and it allows to implement measurements and sampling to study other pigments that are present 
in the paintings. To our knowledge, this is the first study that uses paintings from this artist, we therefore encourage further studies in paintings of Vespasiano Bignami located in Italy to create a full data base of this remarkable artist.

\section{Supplementary information}

Supplementary information accompanies this paper at https://doi. org/10.1186/s40494-020-00470-4.

Additional file 1: Figure S1. Experimental data showing the UV lamp emission spectra (red circles) along with the fluorescent pigment (black circles). Figure S2. Panorama of The Poetry in the IR region. Figure S3. Panorama of The Poetry in IRFC. Figure S4. Panorama of The Dance in the IR region. Figure S5. Panorama of The Dance in IRFC. Figure S6. Panorama of The Music in the IR region. Figure S7. Panorama of The Music in IRFC.

\section{Abbreviations}

AIC: American Institute for Conservation; CHSOS: Cultural Heritage Science Open Source; FWHM: Full width at half maximum; IR: Near infrared; IRFC: False colour infrared; SERS: Surface Enhance Raman spectroscopy; UVF: Ultraviolet fluorescent; UV: Ultraviolet; Vis: Visible.

\section{Acknowledgements}

We thank the National Theatre of Costa Rica for all the logistic and making possible to carried out this study. We also would like to thank Centro de Electroquímica y Energía Química for the access to Origin ${ }^{\circledR}$ software. We give special thanks to Karen Wang-Qiu and Tatiana Zúñiga-Salas from the School of Arts at the University of Costa Rica for their effort in creating the graphical abstract as an unique piece of artwork from our research. We are grateful for the support given by the Vicerrectoría de Investigación at the Universidad de Costa Rica to carry out this research work.

\section{Authors' contributions}

GCB: Performed the experimental work for the technical photographs and UV-Vis spectroscopy measurements, EL: Contributed with the experimental set up for technical photography and images processing, CM: Helped with the experimental set up in the National Theatre of Costa Rica and developed the historical context of Vespasiano Bignami. OAHS: conceived and led the project, was involved in experimental design, data analysis and interpretation. GCB: Wrote the first draft manuscript and all co-authors discussed the results, and commented on the manuscript. All authors read and approved the final manuscript.

\section{Funding}

Funding were support with the projects 726-B8-142 and 816-B7-809 of Vicerrectoría de Investigación of Universidad de Costa Rica.

\section{Availability of data and materials}

The data will be available upon request.

\section{Competing interests}

The authors declares that they have no competing interests.

\begin{abstract}
Author details
${ }^{1}$ Escuela de Química, Universidad de Costa Rica, 2060 San Pedro, San José, Costa Rica. ${ }^{2}$ Centro de Investigación en Ciencia e Ingeniería de Materiales (CICIMA), Universidad de Costa Rica, 2060 San Pedro, San José, Costa Rica. ${ }^{3}$ Instituto de Investigaciones en Arte (IIARTE), 2060 San Pedro, San José, Costa Rica. ${ }^{4}$ Teatro Nacional de Costa Rica, San José 5015-1000, Costa Rica. ${ }^{5}$ Escuela de Física, Universidad de Costa Rica, 2060 San Pedro, San José, Costa Rica. ${ }^{6}$ Centro de Investigación en Ciencias Atómicas Nucleares y Moleculares (CICANUM), Universidad de Costa Rica, San José 2060, Costa Rica.
\end{abstract}

Received: 15 September 2020 Accepted: 25 November 2020 Published online: 03 December 2020
References

1. Hao Z, lqbal A. Some aspects of organic pigments. Chem Soc Rev. 1997;26:203-13.

2. Lee D. Nature's Palette the science of plant color. Chicago: The University of Chicago Press; 2007.

3. Phipps E. Cochineal red: the art history of a color. New York: Metropolitan Museum of Art; 2010

4. Dooley KA, Chieli A, Romani A, Legrand S, Miliani C, Janssens K, Delaney JK. Molecular Fluorescence Imaging Spectroscopy for Mapping Low Concentrations of Red Lake Pigments: Van Gogh's Painting The Olive Orchard. Angew Chem Int. 2020. https://doi.org/10.1002/anie.201915490.

5. Schweppe H, Roosen-Runge H. Carmine. In: Feller RL, editor. Artist A Handb their Hist Charact, vol. 1. Washington, D.C.: Archetype Publications; 1986. p. 255-85.

6. Schweppe H, Winter J. Madder and Alizarin. In: FitzHugh West E, editor. Artist A Handb their Hist Charact, vol. 3. London: Archetype Publications; 1997. p. 23-359.

7. Farnsworth M. Second Century B.C. Rose Madder from Corinth and Athens. Am J Archaeol. 1951;55:236-9.

8. Miliani C, Daveri A, Spaabaek L, Romani A, Manuali V, Sgamellotti A, et al. Bleaching of red lake paints in encaustic mummy portraits. Appl Phys A Mater Sci Process. 2010;100:703-11.

9. Mounier A, Le Bourdon G, Aupetit C, Lazare S, Biron C, Pérez-Arantegui J, et al. Red and blue colours on 18th-19th century Japanese woodblock prints: In situ analyses by spectrofluorimetry and complementary noninvasive spectroscopic methods. Microchem J. 2018;140:129-41.

10. Marcaida I, Maguregui M, Morillas H, Prieto-Taboada N, de Vallejuelo SFO, Veneranda $\mathrm{M}$, et al. In situ non-invasive characterization of the composition of Pompeian pigments preserved in their original bowls. Microchem J. 2018;139:458-66.

11. Daniels V, Devièse T, Hacke $M$, Higgitt $C$. Technological insigths into madder pigment production in antiquity. Tech Res Bull. 2014;8:13-28.

12. Kirby J, White R. The identification of Red Lake Pigment Dyestuffs and a discussion of their use. Natl Gall Tech Bull. 1996;17:56-80.

13. Fieser LF. The discovery of synthetic alizarin. J Chem Educ. 1930;7:2609-33.

14. René de la Rie E. Fluorescence of Paint and Varnish Layers (Part I). Stud Conserv. 1982;27:1-7.

15. Campanella B, et al. Mult-technique characterization of madder lakes: a comparison between non- and micro-destructive methods. J Cult Herit. 2018;33:208-2012.

16. Berrie $\mathrm{BH}$. An improved method for identifying red lakes on art and historical artifacts. PNAS. 2009;106:15095-6.

17. Barni M, Pelagotti A, Piva A. Image processing for the analysis and conservation of paintings: opportunities and challenges. IEEE Signal Process Mag. 2005;22:141-4.

18. Braun E. Introduction: easel painting in the age of Italian unification. J Mod Ital Stud. 2013;18:205-10.

19. Pernich E, Vichi Andrea C. Bignami Vespasiano. Bignami Vespasiano; 2009. http://siusa.archivi.beniculturali.it/cgi-bin/pagina.pl?TipoPag=prodp ersona\&Chiave=47949. Accessed 17 June 2019.

20. Trichies S, Rossi F. Filosofo, Bignami Vespasiano detto Vespa; 2018. http://www.lombardiabeniculturali.it/opere-arte/schede/C0050-00742 /?view=autori\&offset=1\&hid=1057\&sort=sort_int. Accessed 17 June 2019.

21. Tamanini F, Nenci C. La lezione di botanica, Bignami, Vespasiano detto Vespa; 2013. http://www.lombardiabeniculturali.it/opere-arte/sched e/4t020-00087/?view=autori\&offset=0\&hid=31785\&sort=sort_int. Accessed 17 June 2019.

22. Bacuzzi P, Caramel L, Rovetta A. Ritratto di Ignazio Peregalli, Bignami Vespasiano; 2013. http://www.lombardiabeniculturali.it/opere-arte/sched e/3n070-00013/?view=autori\&hid=20847\&sort=sort_int\&offset=3. Accessed 17 Jun 2019.

23. Bacuzzi P, Caramel L, Rovetta A. Ritratto di Francesco Osculati, Bignami Vespasiano; 2013. http://www.lombardiabeniculturali.it/opere-arte/sched e/3n070-00037/?view $=$ autori\&hid $=20847 \&$ sort=sort int\&offset $=2$. Accessed 17 Jun 2019.

24. Pola F, Galimberti PM. Ritratto di Achille Nebuloni, Bignami Vespasiano; 2013. http://www.lombardiabeniculturali.it/opere-arte/schede/3n040 $-00048 /$ ? view =autori\&offset=1\&hid=20847\&sort=sort_int. Accessed 17 June 2019. 
25. Salazar Oviedo M, Santamaría ML. Mercato Culturale: El nacimiento de la ornamentación de un coliseo. Diálogos. 2015;16:27-57.

26. Santamaría Montero L. Análisis de la conformación del diseño arquitectónico y ornamental del Teatro Nacional de Costa Rica. Universidad de Costa Rica; 2017.

27. Morice JG, Benavides-Rodríguez J, Conejo-Barboza G, Marín C, Montero ML, Herrera-Sancho OA. A Brief Insight Into the Secrets of the 120-YearOld Main Curtain of the National Theatre of Costa Rica Through Non-Destructive Characterization Techniques. J Conserv Museum Stud. 2019;17:1-10

28. U.T. Gli artefici italiani d'un teatro di Costarica. Le vie d'Italia e dell'America Lat. 1927;33:406-12

29. G.N. Le Carte di Vespasiano Bignami donate da Carlo Bozzi alla Biblioteca D`Arte del Castello. Riviste Mens del Comune. Milano; 1942;313-7.

30. Cosentino A. Pigments Checker v.5. Pigment. Checker; 2019. p. 1-15. https://chsopensource.org/pigments-checker/. Accessed 26 Aug 2019.

31. Garrido J. Anteproyecto sobre las obras de conservación y restauración de las pinturas de los plafones en los cielos rasos del Teatro Nacional de San José de Costa Rica; 1971.

32. Garrido J. Primer Informe sobre el tratamiento de las pinturas en la sala del Foyer del Teatro Nacional en San José de Costa Rica; 1971.

33. Del Valle C. Primera Etapa del trabajo realizado en el Teatro Nacional de San José de Costa Rica. Costa Rica: San José; 1977.

34. Del Valle C. Referencia de los trabajos realizados en la segunda fase de la restauración del Teatro Nacional San José (Costa Rica); 1978.

35. Del Valle $C$. Referencia a los trabajos realizados en la tercera fase y final de la restauración de las pinturas de Teatro Nacional de San José de Costa Rica; 1980.

36. Webber SL. Technical Imaging of Paintings. Williamst Art Conserv Cent Tech Bull. 2008;3:1-5.

37. Carden ML. Use of ultraviolet light as an aid to pigment identification. APT Bull. 2006;23:26.

38. Kirby J, Spring M, Higgitt C. The technology of eighteenth- and nineteenth-century red lake pigments. Natl Gall Tech Bull. 2007;28:69-95.

39. Gueli AM, Bonfiglio G, Pasquale S, Troja SO. Effect of particle size on pigments colour. Color Res Appl. 2017;42:236-43.

40. Verri G, Opper T, Deviese T. The, "Treu Head": a case study in Roman sculptural polychromy. Br Museum Tech Res Bull. 2010;4:39-54.

41. Claro A, Melo MJ, Seixas de Melo JS, van den Berg KJ, Burnstock A, Montague $\mathrm{M}$, et al. Identification of red colorants in van Gogh paintings and ancient Andean textiles by microspectrofluorimetry. J Cult Herit. 2010;11:27-34

42. Pelagotti A, Pezzati L, Bevilacqua N, Vascotto V, Reillon V, Daffara C. A study of UV fluorescence emission of painting materials. In: 8th international conference non-destructive investigations and microanalysis diagnostics conservation of cultural and environmental heritage. Lecce, Italy; 2005.

43. Claro A, Melo MJ, Schäfer S, Seixas Melo JS, Pina F, van den Berg KJ, et al. The use of microspectrofluorimetry for the characterization of lake pigments. Talanta. 2008;74:922-9.

44. Johnston-Feller R. Color science in the examination of museum objects nondestructive procedures. Ball T, editor. Los Angeles: The J. Paul Getty Trust; 2001.

45. Kirby J, Spring M, Higgitt C. The technology of red lake pigments manufacture: Study of the Dyestuff substrate. Natl Gall Tech Bull. 2005;26:71-87.

46. Clementi C, Miliani C, Verri G, Sotiropoulou S, Romani A, Brunetti BG, et al. Application of the Kubelka-Munk correction for self-absorption of fluorescence emission in carmine lake paint layers. Appl Spectrosc. 2009;63:1323-30

47. Clementi C, Doherty B, Gentili PL, Miliani C, Romani A, Brunetti BG, et al. Vibrational and electronic properties of painting lakes. Appl Phys A Mater Sci Process. 2008;92:25-33.

48. Clementi C, Rosi F, Romani A, Vivani R, Brunetti BG, Miliani C. Photoluminescence properties of zinc oxide in paints: a study of the effect of self-absorption and passivation. Appl Spectrosc. 2012;66:1233-41.

49. Saunders D, Kirby J. Light-induced colour changes in red and yellow lake pigments. Natl Gall Tech Bull. 1994;15:79-97.

50. Cosentino A. Identification of pigments by multispectral imaging; a flowchart method. Herit Sci. 2014;2:1-12.

51. Thoury M, Elias M, Frigerio JM, Barthou C. Nondestructive varnish identification by ultraviolet fluorescence spectroscopy. Appl Spectrosc. 2007;61:1275-82

\section{Publisher's Note}

Springer Nature remains neutral with regard to jurisdictional claims in published maps and institutional affiliations.

\section{Submit your manuscript to a SpringerOpen ${ }^{\circ}$ journal and benefit from:}

- Convenient online submission

- Rigorous peer review

- Open access: articles freely available online

- High visibility within the field

- Retaining the copyright to your article

Submit your next manuscript at springeropen.com 